\title{
JOACHIM DU BELLAY, Le antichità di Roma
}

\section{Dario Cecchetti}

\section{(2) OpenEdition \\ Journals}

\section{Edizione digitale}

URL: http://journals.openedition.org/studifrancesi/32987

DOI: 10.4000/studifrancesi.32987

ISSN: 2427-5856

\section{Editore}

Rosenberg \& Sellier

\section{Edizione cartacea}

Data di pubblicazione: 1 décembre 2005

Paginazione: 626

ISSN: 0039-2944

\section{Notizia bibliografica digitale}

Dario Cecchetti, «JOACHIM du bellay, Le antichità di Roma», Studi Francesi [Online], 147 (XLX | III) | 2005, online dal 01 novembre 2015, consultato il 19 avril 2021. URL: http://journals.openedition.org/ studifrancesi/32987 ; DOI: https://doi.org/10.4000/studifrancesi.32987

Questo documento è stato generato automaticamente il 19 avril 2021.

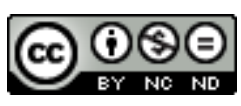

Studi Francesi è distribuita con Licenza Creative Commons Attribuzione - Non commerciale - Non opere derivate 4.0 Internazionale. 


\title{
JOACHIM DU BELLAY, Le antichità di Roma
}

\author{
Dario Cecchetti
}

\section{NOTIZIA}

JOACHIM DU BELLAY, Le antichità di Roma, a cura di PATRIZIO TUCCI, Roma, Carocci («Piccola Biblioteca Letteraria», 22), 2005, pp. 108.

1 Patrizio Tucci pubblica, riproponendo il testo a cura di H. Chamard, le Antiquitez de Rome (col corollario del Songe), e le accompagna con una nitida traduzione a fronte e con annotazioni puntuali. Questa edizione, che compare in una collezione finalizzata all'insegnamento universitario e agli studenti di livello avanzato, fornisce anche uno strumento valido allo studioso in quanto fa il punto della critica (esauriente e aggiornata è la bibliografia) e costruisce una convincente interpretazione d'insieme che ribadisce come Du Bellay sia «il primo poeta francese del Rinascimento a fondere in una stessa opera la tradizione moralistica di ascendenza cristiana e la tradizione apologetica antica». Soprattutto prendendo le distanze da interpretazioni correnti (quelle di G. Gadoffre, ad esempio), Tucci non vuole caricare troppo di sensi religiosi e politici di attualità un testo che, sicuramente, fa riferimento polemico (nazionalistico, soprattutto) alla realtà del tempo, ma che non può essere considerato soltanto una messa in scena o un travestimento classicheggiante di dibattiti del momento. Anche in rapporto ai Regrets appare evidente la complementarità delle due opere, proprio nel riferimento archeologico che nutre entrambe le raccolte di spiriti antiquarî. Riprendendo una formula di Francesco Orlando, l'A. sottolinea come la caratteristica delle Antiquitez, nel quadro di precise tradizioni classiche (il senso della fatalità) e bibliche (il tema della vanitas universale), sia nell'estetizzazione dei resti antichi e nell'«ammirazione del monumento non benché ma perché corroso e mutilo». In questa prospettiva, viene ricostruito il contesto della sensibiltà antiquaria umanistica, attraverso tutta una serie di richiami a testimonianze che, a partire dai Mirabilia Romae urbis su fino ai furori archeologici cinquecenteschi, a livello di interventi sul campo, a 
livello di riflessione storiografica e a livello iconologico, permettono di ricostruire l'ispirazione delle Antiquitez come fatto squisitamente rinascimentale. 